\title{
O papel da escrita e leitura de resenhas críticas de livros, filmes e CD na educação inicial do professor de língua inglesa ${ }^{1}$
}

\author{
Rafael Leonardo da Silva \\ Vera Lúcia Lopes Cristovão ${ }^{\star \star}$
}

\section{Resumo}

Neste trabalho, procuramos investigar, com base no Interanacionismo Sociodiscursivo, a relação entre o gênero textual resenha crítica de filme/ livro/CD e a formação docente, bem como suas contribuições para o desenvolvimento profissional do futuro professor. Decorrente desse propósito mais amplo, delimitamos nossos objetivos específicos: i) identificar a adequação dos textos produzidos por alunos do curso de Letras Estrangeiras Modernas de uma universidade no norte do Paraná às características prototípicas do gênero; e ii) analisar a contribuição do processo de leitura e escrita desses textos para o desenvolvimento profissional desses alunos-professores. $\mathrm{O}$ gênero foi trabalhado em uma disciplina de compreensão e produção escrita em língua de inglesa por meio de uma sequência didática. Essa consistia em atividades para a aprendizagem das características da resenha crítica, além das possibilidades de reescrita o que possibilitou a observação do processo de desenvolvimento da linguagem es- crita desses indivíduos. A sequência didática se mostra um dispostivo didático relevante para a aprendizagem dos alunos, mas os resultados apontam para particularidades no desenvolvimento de cada indivíduo que compõe o grupo focal desta pesquisa.

Palavras-chave: Gêneros textuais. Educação de professores. Interacionismo sociodiscursivo. Resenha crítica de livros/CD/de filmes.

\footnotetext{
Aluno do mestrado em Estudos da Linguagem no Programa de Pós-Graduação em Estudos da Linguagem da Universidade Estadual de Londrina (UEL). E-mail: rafaelleon2107@gmail.com.

** Professora associada do departamento de Letras Estrangeiras Modernas da Universidade Estadual de Londrina (UEL) e do Programa de Pós-Graduação em Estudos da Linguagem; atuou como orientadora e coautora deste trabalho. Foi coordenadora do Projeto Gêneros Textuais e Educação Inicial do Professor tde Língua Inglesa (GENTEDIPLI) e é líder do grupo de pesquisa Linguagem e Educação. E-mail: veraluciacristovao@gmail.com.
}

Data de submissão: mar. 2014 - Data de aceite: maio 2014 http://dx.doi.org/10.5335/rdes.v10i1.4104 


\section{Introdução}

Nesta pesquisa, buscamos analisar o processo de apropriação do gênero resenha crítica de três alunos do primeiro ano do curso de Letras Estrangeiras Modernas de uma universidade pública do norte do Paraná por meio de uma sequência didática (SD) baseada no referencial teórico do Interacionismo Sociodiscursivo (ISD), que pretende examinar as contribuições da linguagem para o desenvolvimento do ser social (BRONCKART, 2006, 2008). Baseamo-nos, também, em teorizações de Barras (1986) e Khunkitti (2005) em relação a resenhas críticas e sua estrutura, levando em considerações as estruturas apresentadas para a análise realizada.

Utilizando como dados textos oriundos de uma sequência didática que visava à apreensão do gênero resenha crítica de livros, filmes e CDs, temos como objetivos: i) identificar a adequação dos textos às características prototípicas do gênero por parte dos alunos-professores; e ii) analisar a contribuição do processo de leitura e escrita desses textos para o desenvolvimento profissional dos alunos em foco.

O texto expõe a fundamentação teórica com os conceitos-chave que ancoram a pesquisa, a saber, os gêneros textuais, $o$ gênero resenha crítica e a importância desse para o desenvolvimento do aluno, tanto na educação básica como em um contexto acadêmico. Além disso, descrevemos a metodologia adotada para analisarmos as produções, pautada no suporte teórico- -metodológico do ISD (BRONCKART, 2006; 2008), e, na sequência, apresentamos e discutimos os resultados da análise. Por fim, tecemos considerações finais referente à relação entre o gênero resenha crítica e a educação de inicial de professores de língua inglesa.

\section{Os gêneros textuais na perspectiva do Interacionismo Sociodiscursivo}

O Interacionismo Sociodiscursivo (ISD) é uma corrente teórico-metodológica que visa analisar o funcionamento da linguagem e sua contribuição para o desenvolvimento humano (BRONCKART, 2006; 2008). Diversas discussões sobre gêneros (SWALES, 1990; BRONCKART, 1999) e suas definições provêm de Bakhtin (1992, p. 297), que os define como "formas relativamente estáveis e normativas de enunciados", formas de interação social, sem as quais não existiria comunicação.

Para Bakhtin, os gêneros são classificados em gêneros primários e secundários. $\mathrm{O}$ autor discorre que os gêneros primários são os imediatos da comunicação e não possuem muita complexidade, como uma conversa ou um simples recado. Os gêneros que demandam uma estrutura mais complexa são denominados gêneros secundários. A resenha, gênero textual utilizado neste estudo, é um exemplo de gênero secundário.

Por um lado, a dinamicidade do gênero, descrita pelo autor, se dá na 
geração de novos gêneros primários e secundários devido a várias transformações sociais e necessidades contextuais. Por outro lado, é importante salientar a característica "relativamente estável" do gênero, pois a forma com que o mesmo é produzido pode variar conforme a atividade discursiva em que os interlocutores estão inseridos (BRONCKART, 1999). Mesmo em diferentes contextos, épossível identificar uma atividade de linguagem como pertencente a um gênero específico.

No ISD, os gêneros de textos

[...] constituíam os produtos de configurações de escolhas entre as possíveis, que são momentaneamente estabilizadas pelo uso, escolha que emerge do trabalho que realiza as formações sócio-discursivas para que os textos sejam adaptados às atividades que eles praticam, adaptados a um meio comunicativo dado, eficazes em face a tal aposta social, etc (BRONCKART, 2006, p. 13).

No entanto, mesmo que alguns gêneros possam ser reproduzidos em diferentes meios, como é o caso da resenha crítica, outros ficam restritos a uma única esfera de interação, como é o caso do culto e da missa, presentes eminentemente na esfera religiosa. Ademais, a quantidade de gêneros existentes pode ser considerada infinita, por caracterizarem atividades de linguagem que se modificam e se reinventam constantemente, além da criação de novas formas de interação devido, entre outros motivos, aos recentes avanços tecnológicos.

No contexto educacional brasileiro, temos observado, nos últimos anos, um aumento na preocupação em oferecer um ensino mais contextualizado, o que pode, aliás, ser observado nos PCN de Língua Estrangeira (BRASIL, 1998). Por isso, o trabalho com gêneros textuais tem sido cada vez mais integrado ao ensino de línguas. Uma abordagem com base em gêneros contempla a apresentação aos alunos de textos autênticos que circulam em esferas sociais, às quais são expostos diariamente, auxiliando-os a pensar criticamente a respeito de tais produções.

Esses textos sociais, ao serem utilizados na esfera escolar, ganham um objetivo didático e são usados/consumidos diferentemente de sua esfera de produção e circulação social, dada a sua apropriação para fins didáticos (DOLZ; SCHNEUWLY, 2004). Cabe ao professor, então, promover oportunidades de uso desse gênero para que características do agir com tal gênero possam ser contempladas com um trabalho de sala de aula, objetivando que os alunos não aprendam somente mecanismos de textualização, mas também o agir com a linguagem em situações e em contextos específicos, contextualizando, assim, o ensino.

Os gêneros textuais, tanto na educação básica quanto na educação inicial do professor de língua estrangeira, categoria a qual pertencem os sujeitos desta pesquisa, podem ser trabalhados por meio de uma sequência didática, que segundo Cristovão (2009, p. 4):

a) permite um trabalho integrado; b) pode articular conteúdos e objetivos sugeridos por orientações oficiais (Diretrizes Curriculares, por exemplo) com aqueles do contexto específico (Projeto Político-pedagógico ou 
planejamento anual); c) contempla atividades e suportes (livro, internet etc.) variados; d) permite progressão a partir de trabalho individual e coletivo; e) possibilita a integração de diferentes ações de linguagem (leitura, produção escrita etc.) e de conhecimento diversos; f) adapta-se em função da diversidade das situações de comunicação e das classes.

A autora também atenta para a importância da utilização de "textos sociais (de circulação real)" em sala de aula, pois assim o aluno terá contato com diferentes esferas sociais em que textos pertencentes a determinados gêneros são produzidos e circulam. É, também, com textos sociais que a relação texto-contexto pode ser explorada.

Salientamos, portanto, a função crucial do contexto de produção para a presente pesquisa. Os textos produzidos pelos alunos-professores foram avaliados em relação às três capacidades de linguagem que, segundo Dolz e Schneuwly (2004, p. 54) são “aptidões requeridas do aprendiz para a produção de um gênero numa situação de interação determinada". Ou seja, para a produção de um texto de um gênero específico, o aprendiz deve estar ciente das capacidades de linguagem envolvidas em sua produção, bem como se apropriar das características prototípicas do gênero. A SD, como dispositivo didático, almeja propiciar espaços para essa apropriação.

As capacidades de linguagem são constituídas por capacidades de ação, discursivas e linguístico-discursivas. Porém, mesmo que elas sejam avaliadas separadamente, todas estão interligadas e contribuem para que o aluno se apro- prie das características prototípicas do gênero (CRISTOVÃO, 2009).

As capacidades de ação (C.A.), segundo Cristovão (2009, p. 321),

[...] possibilitam ao sujeito adaptar sua produção de linguagem ao contexto de produção, ou melhor, às representações do ambiente físico, do estatuto social dos participantes e do lugar social onde se passa a interação.

As C.A. permitem ao aluno situar seu texto em um contexto específico, levando em consideração por quem esta produção foi escrita, para quem, onde e quando foi produzido, circulada e consumida, com que objetivo, sobre o quê e de que forma.

As capacidades discursivas (C.D.), por sua vez, de acordo com Cristovão,

[...] possibilitam ao sujeito escolher a infraestrutura geral de um texto, ou seja, a escolha dos tipos de discurso e de sequências textuais, bem como a escolha e elaboração de conteúdos, que surgem como efeito de um texto já existente e estímulo para outro que será produzido (2009, p. 321).

Nesse sentido, as capacidades discursivas permitem ao aluno organizar o conteúdo do texto conforme as caraterísticas prototípicas do gênero proposto, as quais não representam uma estrutura fixa. O texto do aluno não precisa necessariamente ser composto de todas as características prototípicas, porém, é importante que o conteúdo do texto esteja organizado de modo que seja socialmente reconhecido como texto pertencente ao gênero trabalhado.

Já as capacidades linguístico-discursivas (C.L.D.) 
[...] possibilitam ao sujeito realizar as operações implicadas na produção textual, sendo elas de quatro tipos: as operações de textualização, sendo elas a conexão, coesão nominal e verbal; os mecanismos enunciativos de gerenciamento de vozes e modalização; a construação de enunciados, orações e período; e, finalmente, a escolha de itens lexicais" (CRISTOVÃO, 2009, p. 321).

$\mathrm{O}$ aluno também tem a possibilidade de expandir seu vocabulário devido aos aspectos linguísticos específicos do gênero trabalhado em sala de aula, como, por exemplo, uma grande variedade de adjetivos. Essas capacidades podem contribuir para que o autor pareça mais ou menos implicado no texto.

\section{O Gênero Resenha Crítica}

Definimos o gênero resenha crítica como um resumo de uma determinada obra com a função de informar elementos de avaliação sobre essa produção. Para estudiosos do gênero resenha crítica, a avaliação é constitutiva e fulcral nesse gênero de texto. Temos as resenhas acadêmicas, comumente publicadas em periódicos da área do conhecimento e as resenhas críticas de produções culturais diversas como filmes, CD, livros, entre outros.

A resenha, nos dias de hoje, está presente em diversos meios de comunicação, como, por exemplo, na internet, rádio, televisão, jornais e revistas de circulação nacional ou até mesmo mundial. As resenhas são, em sua maioria, produzidas por jornalistas. Podemos encontrar, no entanto, textos pertencentes a este gênero publicados na internet escritos por indivíduos não-jornalistas.
A produção tem diferentes finalidades, uma delas é divulgar a obra ou apresentar uma avaliação desta em um meio específico. Para isso, é utilizado um discurso opinativo e argumentativo, com linguagem avaliativa como principal recurso de linguagem e modalização em diferentes graus de intensidade, bem como organizadores lógico-argumentativos como conectivos.

Khunkitti (2005) organiza a resenha em uma série de movimentos e passos (as subunidades dos movimentos), um modelo que é utilizado para orientar o leitor e, também o produtor do texto. Nos movimentos, haveria, inicialmente, a introdução da obra; depois, um breve resumo dessa, podendo-se destacar partes importantes da produção; também uma avaliação do resenhista sobre a obra, para depois concluir o seu texto, recomendando-a ou não.

Barras (1986, s.p.), por sua vez, sugere que o produtor da resenha seja capaz de responder certas perguntas em seu texto. No caso, o autor utilizou o exemplo das resenhas de livros.

De que se trata o livro? Tem ele alguma característica especial? De que modo o assunto é elaborado? Que conhecimentos prévios são exigidos para entendê-lo? A que tipo de leitor se dirige o autor? $\mathrm{O}$ tratamento dado ao tema é compreensivo? O livro foi escrito de modo interessante e agradável? As ilustrações foram bem escolhidas? O livro foi bem organizado? O leitor, que é a quem o livro se destina, irá achá-lo útil? Que resulta da comparação dessa obra com outras similares (caso existam) e com outros trabalhos do mesmo autor? 
Os dois autores concordam quanto à organização geral do texto, mesmo que Khunkitti (2005) apresente uma lista de movimentos e Barras (1986) uma série de perguntas.

Produzida para divulgar um filme, a resenha cinematográfica foi um dos gêneros da resenha trabalhados em sala de aula. Segundo Barros (2009, p. 182), a resenha cinematográfica

[...] tem como tema principal certa obra cinematográfica - alvo da crítica. O objetivo comunicativo do gênero transita entre a apresentação de informações do filme (data de estréia, gênero cinematográfico, duração, diretores, atores, etc.), a sumarização do enredo e a asserção valorativa de alguns aspectos da obra.

Essas outras características da obra apresentam uma diferenciação entre a resenha cinematográfica e as outras estudadas neste trabalho. Observamos, por meio da análise do corpus, além de descrição do enredo e do julgamento do resenhista em relação a mesma, que outros aspectos da obra cinematográfica também são analisados, como as atuações, os efeitos visuais e a trilha sonora.

O resenhista geralmente descreve a obra levando em conta o enredo e a linguagem utilizada para que a história seja contada. Além disso, nesse gênero, o autor da obra se faz mais presente - em algumas resenhas, há um julgamento da obra levando em conta os trabalhos anteriores do escritor.

Já a resenha de livros, não é apresentada somente em uma forma: daí o caráter "relativamente estável" do gênero
(BAKHTIN, 1992). Em textos escritos por fãs, há uma maior implicação do autor da resenha. Este dá a sua opinião de maneira mais assertiva, mais objetiva, recomendando a obra e baseando-se na sua própria apreciação. Com base na análise do corpus de textos escritos por jornalistas, observamos que a implicação é praticamente inexistente - seguindo normas da publicação, o autor da resenha descreve a obra apresentando seus pontos positivos e negativos, sem, no entanto, expressar a sua própria opinião de forma mais aberta ou assertiva.

Ademais, os textos pertencentes ao gênero resenha crítica de CD têm como objetivo analisar uma obra musical. $\mathrm{O}$ álbum, inédito ou não, é avaliado pelo resenhista pela qualidade das letras das músicas, do estilo musical e do impacto causado pelaobra, em comparação com outros CDs do mesmo artista, ou de outros artistas do mesmo estilo musical. Assim, como a resenha de livros, também possui várias formas de estruturação. Pode ser avaliado o álbum como um todo, apresentando características comuns a todas as músicas e as canções que se destacam, assim como também pode ser feita uma crítica música por música, descrevendo cada faixa do álbum e avaliando-a.

A resenha crítica em si, geralmente, é trabalhada em sala de aula pelo seu auxílio no exercício do pensamento crítico e sua facilidade de acesso, uma vez que este gênero está presente em várias mídias, como jornais, revistas e sites de 
internet. Berbare (2004) afirma que a resenha crítica é um gênero importante em sala de aula, por desenvolver também as capacidades de linguagem de produção e de compreensão escrita em qualquer nível da formação.

É importante que, desde os primeiros anos da educação escolar, o aluno seja acostumado a produzir textos argumentativos, para exercitar uma leitura mais crítica. Verificamos isso em matéria da revista Nova Escola (Março de 2007, p. 88-89). Essa matéria, relata experiências em que os alunos são expostos a diferentes gêneros literários (contos de fada, contos modernos, fábulas, etc.) até mesmo antes da aprendizagem da escrita. Tal abordagem foi feita em uma creche de São Paulo. Depois da produção das resenhas, essas foram expostas em uma Feira Cultural do Livro.

Os objetivos de abordar o gênero resenha, segundo a revista Nova Escola, são formar "bons leitores e escritores" e "ensinar a socializar os livros prediletos". Também, é relatada a importância que os alunos conheçam "muito bem os livros que serão indicados (e gostar deles)" (Revista Nova Escola, março de 2007), indicando que gostar da obra é um importante fator motivacional na produção da resenha.

O ensino da resenha crítica na escola e na universidade, porém, possui algumas diferenças. Enquanto na escola, o objetivo é desenvolver a leitura e a escrita crítica, no meio acadêmico, Vian Jr. e Ikeda (2009, p. 15) defendem que o trabalho com resenhas
[...] permite, em um primeiro momento, a familiarização dos alunos com o gênero. Ao passo que vão se tornando usuários constantes do gênero, os alunos ampliam e reforçam seu conhecimento sobre gêneros, o que permite sua inserção na comunidade discursiva, transformando-a, depois, em uma atividade de ensino e de pesquisa.

Na universidade, o aluno pode estudar mais atentamente a estrutura da resenha crítica, a fim de aprender sua organização e auxiliar uma possível abordagem deste gênero em sala de aula. Além disso, a aprendizagem beneficia o aluno, auxiliando-o a produzir resenhas que possam ser necessárias em meio acadêmico.

\section{Metodologia}

\section{Contexto de Pesquisa e de Produção dos Textos}

A pesquisa foi realizada por meio da análise de resenhas críticas de $\mathrm{CDs}$, filmes e livros, escritas por três alunos do primeiro ano de Letras Estrangeiras Modernas em uma universidade pública do norte do Paraná para a disciplina Compreensão e Produção Escrita em Língua Inglesa I.

Esta disciplina tem o objetivo de desenvolver as capacidades de produção escrita do aluno por meio do trabalho com gêneros textuais. São vários os gêneros trabalhados em sala de aula, e, destes, cada aluno produz uma primeira, segunda e terceira versões. Durante o trabalho, também são apresentados textos que servem como referências do gênero 
e os alunos podem utilizá-los como base para a produção de seus próprios textos.

Os três alunos-professores selecionados como o grupo focal desta pesquisa, José, Hugo e Luiza, foram escolhidos, entre trinta alunos de turmas vespertina e noturna do curso, devido às últimas produções em sala de aula, voltaram-se para a resenha de um livro, um filme ou um CD. Cada participante da pesquisa escolheu um desses três subgêneros para sua produção final.

Os alunos selecionados para o grupo focal foram, assim escolhidos, por apresentarem diferenças visuais que pareciam revelar uma aprendizagem do gênero trabalhado em classe ao cotejarmos suas diferentes produções.

Como o trabalho inicial com a turma revelou uma preferência pelo gênero musical rock n`roll, inicialmente, os alunos foram apresentados ao álbum Chinese Democracy, da banda Guns n' Roses, por meio de um vídeo de um show ao vivo, que pôde ser encontrado em um site da internet. Sem a menção da professora em relação à estrutura e à linguagem de uma resenha, foi solicitado aos alunos que produzissem a sua primeira versão de uma resenha apenas usando o seu conhecimento prévio a respeito do gênero, assim como em relação ao álbum e à banda.

A aula seguinte iniciou com uma discussão baseada em dez perguntas que contemplavam: a) gosto por livros, música, filmes ou teatro e a justificativa; b) a frequência desses hobbies; c) a pos- sibilidade de se ter (ou não) tais hobbies; d) a forma de escolher o que ler, ouvir e/ ou assistir (no cinema ou teatro); e) os conhecimentos acerca de resenha como autoria, destinatário, contexto, mídia de veiculação, conteúdo e finalidade dos leitores em ler resenhas. Como atividade subsequente, os alunos leram as descrições sobre o site de uma revista que publica resenhas escritas por jornalistas e um blog musical com resenhas produzidas por fãs. Depois de comentarem as especificidades de cada mídia, leram uma resenha de cada site e buscaram tanto informações factuais como autoria, destinatário, conteúdo e propósito como uma reflexão sobre como essas características impactam na resenha e em seu propósito. Depois dessa discussão, os alunos-professores expressaram a insatisfação de terem tido que escrever uma resenha relacionada a um conteúdo que não dominavam, pois poucos assumiram conhecer suficientemente o álbum Chinese Democracy. Em outras palavras, houve ampla refexão e tomada de consciência sobre conhecer o conteúdo do que se quer resenhar como condição sine-que-non para se escrever uma boa resenha. Como tarefa, os alunos deveriam trazer uma resenha do bem cultural sobre a qual gostariam de resenhar.

Nas próximas aulas, os alunos foram introduzidos a características (movimentos e passos) de produção de resenhas, segundo Khunkitti (2005), e também foram apresentados a diferentes exemplares de resenhas, mais uma trazida 
pela professora quanto aquelas escolhidas pelos alunos para serem lidas e trabalhadas em sala de aula. Utilizando-se desse conjunto de características e dos exemplos encontrados, puderam observar a adequação de seus próprios textos ao gênero. Em seguida, em sala de aula, e juntamente a dois outros colegas (a outros três, no caso de José) produziram a primeira refacção, ou a segunda versão de sua resenha, ainda do mesmo álbum trabalhado anteriormente em sala de aula.

$\mathrm{O}$ objetivo de tais atividades realizadas entre a primeira e a segunda produções foi conscientizar o aluno das capacidades de ação e discursivas envolvidas no gênero textual estudado. Os textos dos alunos foram avaliados, justamente, conforme essas capacidades. Na segunda produção, além de adequar os seus textos à lista de movimentos e passos, os alunos puderam introduzir ideias novas em suas produções com a ajuda de outros conhecimentos que os colegas teriam sobre o álbum.

$\mathrm{Na}$ sequência, os alunos analisaram textos pertencentes ao gênero trabalhado em classe, observando-os atentamente, e de certa forma, avaliando a adequação desses textos ao gênero e estudando algumas características próprias de cada subgênero da resenha crítica. A ênfase das análises nesse momento centrava-se nos recursos avaliativos, coesivos e de conexão usados nas resenhas lidas. Observou-se o uso de grupos nominais, linguagem avaliativa, organizadores lógico-argumentativos e modalizações, indicando o grau de intensidade da avaliação e linguagem formal ou informal em função do autor e da mídia de veiculação.

A última refacção, a versão final, foi escrita individualmente. Nessa versão, os alunos produziram os seus textos em suas casas e puderam resenhar quaisquer CD, livros e/ou filmes que desejassem escolhidas como subgêneros para a última refacção. Nossa ivestigação analisou as produções dos alunos Hugo, José e Luiza.

\section{Perfil dos Participantes}

Respondendo a um breve questionário para obtenção de seu perfil, o participante Hugo, de 18 anos, baseia-se no certificado que recebeu de uma escola privada de inglês para informar que seu inglês é considerado fluente. Escolheu o curso por ser direcionado a algo que ele gosta, sem ter em mente onde chegaria com o que aprende em sala de aula.

Quanto ao curso de Letras Estrangeiras Modernas - Língua Inglesa, ele revela que as disciplinas excederam suas expectativas. Especificamente em relação à matéria Compreensão e Produção Escrita em Língua Inglesa I, discorre que a disciplina o fez mudar a sua visão a respeito dos gêneros e ensinou-lhe a melhor identificá-los. Também lhe agrada o fato de que foge dos clichês universitários, devendo, segundo ele, a "metodologia da escrita ser voltada para artigos acadêmicos". 
Quando perguntado sobre seus hobbies e gostos pessoais, responde que tem "18 anos muito mal aproveitados", devido a seu gosto por livros de ficção, seriados, filmes e música. Além disso, gosta de Guns n' Roses, mas não do álbum Chinese Democracy, trabalhado em sala de aula. Ainda, ao falar de música, tem como favorita a banda Mettalica.

A aluna-professora, Luiza, reside na mesma cidade em que estuda e considera seu inglês como de nível intermediário, tendo estudado, anteriormente ao curso universitário, um ano e meio em uma escola de idiomas. Apesar de ter optado por um curso de licenciatura em Língua Inglesa, Luiza tem como objetivo trabalhar com tradução.

O curso de Letras Estrangeiras Modernas - Língua Inglesa superou as expectativas de Luiza, que se mostra surpresa com o quanto os professores são atenciosos e como alguns deles trabalham "de uma maneira interdisciplinar". Revela, porém, não gostar de algumas matérias por não considerá-las úteis. A disciplina Compreensão e Produção Escrita em Língua Inglesa I a ajudou a "conhecer diferentes formas de expressão textual".

Tem dezenove anos e ocupa seu tempo livre com livros e filmes, seu "passatempo preferido". Planeja viajar para o exterior ao final do curso, a fim de fazer alguma especialização. Além de desejar trabalhar com tradução, não descarta exercer a função de professora.
A aluna revela não gostar de Guns n' Roses e gostar do filme que resenhou em sua produção final, apesar desse não ser o seu favorito.

O aluno-professor José tem 21 anos, reside na mesma cidade em que estuda e considera o seu nível de inglês entre o básico e o intermediário. O mesmo revela ter conhecimento também da língua japonesa, e justifica a escolha pelo curso de Letras Estrangeiras Modernas - Língua Inglesa devido à ausência de uma graduação em Língua Japonesa na cidade em que reside.

Em relação a seus dados pessoais e objetivos profissionais, o aluno-professor informa ser participante de grupos ligados à Cultura Japonesa, visto que a Língua Japonesa é um de seus maiores interesses. Para o futuro, planeja ser professor de Japonês.

José acredita que as mudanças feitas na grade curricular de seu curso apresentaram uma melhora na qualidade de ensino, revelando um conhecimento prévio das matérias ensinadas antes de seu ingresso na universidade. O participante informa não ter críticas quanto à sequência didática, pois os objetivos das atividades estavam bem claros.

Ao abordar o álbum trabalhado em classe, José discorre gostar de Guns n' Roses, mas revela não ter ouvido $C h i$ nese Democracy. O aluno justifica a sua escolha para a sua produção final, "The Arthur Books" de Bernard Cornwell, por essa série estar em seu "top 10". 


\section{Critérios de Avaliação das Produções}

Tomamos como base o texto de Charoenschasri (2006), trabalhado em sala de aula, para a avaliação dos alunos-professores que formam o grupo focal deste estudo.

$\mathrm{O}$ autor foca em resenhas de filmes produzidos para um dos maiores sites do ramo, o www.imdb.com. A escolha da lista de "movimentos" e "passos" como uma das formas de avaliação para os textos deve-se ao fato de: a) o texto ter sido utilizado em sala de aula, e b) por o gênero resenha ter sido abordado de uma forma sem maiores restrições de palavras ou de vocabulário, ou seja, uma abordagem da resenha em meios virtuais com uso informal da linguagem.

A lista de movimentos de Khunkitti (2005), apresentada aos alunos como um modelo para a produção do gênero, foi baseada na análise de 59 resenhas retiradas de três periódicos em língua inglesa: ESP Journal, ELT Journal e Applied Linguistics. A autora usa estudos anteriores de Swales (1990) e Motta-Roth (1995) para formular a sua lista de movimentos para a produção de resenhas.

Movimento 1 - Introduzir a produção ${ }^{2}$

- Submovimento 1 - Especificando a produção

- Passo 1 - Título da produção

- Passo 2 - Informar sobre público-alvo

- Passo 3 - Inserir a produção em um contexto

- Passo 4 - Breve descrição da produção

- Passo 5 - Destacar algumas partes/pontos da produção
- Submovimento 2-Avaliação pessoal do resenhista

- Passo 1 - Resenhista dá sua posição a ser respeitada

- Submovimento 3 - Fornecer biografia do autor/editor

- Passo 1 - Informações extras para reforçar a credibilidade do autor

Movimento 2 - Descrever a produção

- Passo 1 - Fornecer uma visão geral do conteúdo e organização da produção

- Passo 2 - Comentar brevemente cada ponto/seção da produção

Movimento 3 - Criticar a produção

- Passo 1 - Fornecer comentários positivos

- Passo 2 - Fornecer comentários negativos

- Passo 3 - Fazer sugestões

Movimento 4 - Fornecer avaliação da produção

- Passo 1 - Definitivamente recomendar a produção

- Passo 2 - Recomendar a produção, mas com ressalvas

- Passo 3 - Concluir a resenha sem recomendar a produção

Movimento 5 - Dar outras informações

- Passo 1 - Fornecer referências

- Passo 2 - Fornecer biografia/informações para contato do resenhista

- Passo 3 - Fornecer outras informações

Além dos movimentos e passos supracitados, os procedimentos de análise dos textos basearam-se nas três capacidades de linguagem supracitadas: a) as capacidades de ação, que levam em conta a situação de produção imediata em que os participantes da interação se encontram, ou seja, o produtor do texto, 
seu destinatário, seu objetivo, etc; b) as capacidades discursivas, que analisam a adequação da infraestrutura geral de um texto ao gênero textual proposto; e c) as capacidades linguístico-discursivas, que identificam se os recursos de linguagem utilizados na produção contribuem para o propósito/a função do gênero. Essas categorias de análise servem ao suporte teórico do Interacionismo Sociodiscursivo (DOLZ; SCHNEUWLY, 2004), no qual nos baseamos para este estudo.

Tais capacidades de linguagem foram analisadas nas produções do aluno e puderam ser avaliadas como Não Adequadas (NAD), Parcialmente Adequadas (PAD) e Adequadas (AD). Para isto, são utilizados os seguintes critérios, desenvolvidos com base no corpus reunido e no referencial teórico relacionado ao gênero resenha crítica (BARRAS, 1986; KHUNKITTI, 2005):

\section{(C.A) Capacidades de Ação:}

NAD: Texto não pertencente ao gênero resenha.

PAD: Texto possui características do gênero proposto, mas ainda não está adequado aos elementos de contexto.

AD: Texto é caracterizado como uma produção do gênero proposto, levando em conta o papel do aluno como produtor e os seus possíveis destinatários, ou seja, o professor, outros alunos e possíveis leitores quando de sua disseminação.

(C.D) Capacidades Discursivas:

NAD: Ideias desorganizadas e/ou dispostas de modo incoerente, sem estar de acordo com as características retóricas do gênero proposto (Introdução, Descrição, Crítica, Avaliação e Conclusão).
PAD: Ideias relativamente bem organizadas, mas sem cobrir todos os movimentos essenciais propostos por Khunkitti (2005), ou prolongando-se em um movimento em detrimento de outro.

$\mathrm{AD}$ : Texto organizado segundo os movimentos trabalhados em sala de aula, respeitando as características do gênero resenha crítica e com ideias dispostas de modo coerente.

(C.L.D) Capacidades Linguístico-Discursivas:

NAD: Utilização de recursos de linguagem que não correspondem aos usados em resenhas críticas, também levando em conta inadequações léxico-gramaticais.

PAD: Persistência de erros gramaticais, mesmo que com uma linguagem mais adequada e uma maior utilização de adjetivos em um discurso argumentativo e avaliativo.

$\mathrm{AD}$ : Grande variedade de adjetivos, utilizando uma linguagem adequada ao gênero resenha crítica.

\section{Resultados e discussão das análises}

A presente seção objetiva apresentar a análise de dados na seguinte ordem: primeiro, analisamos as produções iniciais dos sujeitos da pesquisa; em seguida, suas segundas, e, por fim, as terceiras produções. As análises acompanham quadros avaliativos baseados nos critérios na seção metodológica deste estudo.
Primeira Produção: Hugo
C.A. - Contexto - PAD
O texto está parcialmente adequado ao gênero, respeitando as regras de um texto com teor avaliativo e do público- 
-alvo. Possui características de uma resenha escrita sem fins comerciais, uma produção de um fã que se implica no texto.

Não pôde ser considerado adequado por ter, em seu texto, avaliado mais a banda do que o álbum proposto pela professora.

\section{C.D. - Organização de Conteúdo - PAD}

No primeiro texto, o aluno Hugo prolonga-se demais no primeiro movimento, apresentando várias informações sobre a banda em si, sobre sua história e sua formação, como em "Guns ' $n$ Roses released many albums and sold more than 100 million albums worldwide". Até apresenta alguns fatos que poderiam ter influenciado na criação do álbum, mas pouco disserta sobre o CD em si. Ou seja, o movimento é praticamente inexistente.

Hugo apresenta sua opinião pessoal em relação ao álbum, criticando o $\mathrm{CD}$ (Movimento 3), no excerto em que diz "this album can't be considerated the best". O movimento 4 também é breve, concluindo a resenha sem recomendar o álbum: "They are not the same band that rocks in the 90's, but they are still GUNS 'N ROSES'.

C.L.D - Recursos de Linguagem - PAD

O aluno comete erros básicos de tempo verbal e organiza algumas de suas ideias, aparentemente apenas traduzindo-as do português para o inglês, como por exemplo, "Even passing the same message than the other ones (broken hearts, rebellion and misunderstoods)", utilizando o than de maneira inadequada, já que essa palavra é comumente utilizada para comparações na língua inglesa.

Apesar das inadequações, o texto está, razoavelmente bem organizado e suas ideias são apresentadas de forma coerente. Há a predominância da terceira pessoa do plural nos parágrafos introdutórios que falam da banda: "they gave a last move trying to reborn the band after 15 years". Há também o uso do pretérito perfeito (simples) nos parágrafos opinativos, como em "didn't fill fans expectations".

Tabela 1 - Capacidades de Linguagem no Texto I- Hugo

\begin{tabular}{l|c|c|c}
\cline { 2 - 4 } \multicolumn{1}{l|}{} & NAD & PAD & AD \\
\hline C.A & & $X$ & \\
C.D & & $X$ & \\
C.L.D & & $X$ & \\
\hline
\end{tabular}

Fonte: elaborada pelos autores.

\section{Primeira Produção: Luiza}

\section{C.A. - NAD}

Com apenas um parágrafo, a primeira produção da aluna Luiza contém apenas algumas informações sobre a banda, como no excerto "Slash, the band's guitars player, plays guitars very well". Existem alguns elementos de avaliação, por exemplo, em "The musics sounds good, but the lyrics are not so good", mas a aluna avalia a banda, não o álbum Chinese Democracy. 


\section{C.D. - NAD}

As informações estão organizadas de modo coeso no parágrafo único da produção, mas a estrutura não está adequada quanto ao gênero resenha, apresentando apenas uma opinião da aluna e alguma descrição da banda, sem discorrer a respeito do álbum em si.

A banda é introduzida, com uma pequena informação extra ("Slash, the band's guitars player, plays guitars very well"), mas a aluna apresenta sua impressão da banda Guns n' Roses, e não o seu álbum. Logo depois, já finaliza a sua produção, discorrendo sobre o seu desconhecimento de maiores informações relacionadas à banda: "I don't know it very well, but sometimes I listen the musics".

\section{C.L.D - PAD}

Apesar da produção da aluna Luiza ter somente um parágrafo, ainda há algumas características do gênero resenha, como elementos descritivos, na frase introdutória da banda, e alguns adjetivos ("The music sounds good, but the lyrics are not so good").

Tabela 2 - Capacidades de Linguagem no Texto I - Luiza

\begin{tabular}{l|c|c|c}
\cline { 2 - 4 } \multicolumn{1}{l|}{} & NAD & PAD & $A D$ \\
\hline C.A & $X$ & & \\
C.D & $X$ & & \\
C.L.D & & $X$ & \\
\hline
\end{tabular}

Fonte: elaborada pelos autores.

\section{Primeira Produção: José}

\section{C.A. - NAD}

O texto do aluno está inadequado ao gênero proposto. Se parece mais com uma pequena sinopse sobre a banda, não sobre o álbum trabalhado em classe. Com dois parágrafos, apresenta uma breve introdução e informações extras sobre Guns n' Roses, como em "That's what happened with Guns after almost all players leave".

Não existem elementos de avaliação nem da banda trabalhada em classe, nem de seu álbum.

\section{C.D. - NAD}

Nos dois parágrafos que compõem a produção, dos movimentos apresentados por Khunkitti (2005), o aluno somente apresenta dois: uma pequena introdução (Movimento 1), por exemplo, em "We don't know how bands or groups stasrt, we just know them when some success comes. To Guns it came by the '90s", e informações extras, o Movimento 5, em "Now Axl has a new band, but they're trying to play like old times with new players".

Os movimentos 2 , 3, e 4 são inexistentes na primeira produção do aluno José, descaracterizando o texto como pertencente a uma produção do gênero resenha crítica.

\section{C.L.D - NAD}

O aluno José apresenta poucos elementos de avaliação em seu texto, utilizando poucos adjetivos para descrever e expor sua crítica da banda. 
Os erros gramaticais são poucos, como por exemplo, "after all the most players leave", utilizando o verbo no presente do indicativo em vez de pretérito perfeito.

Tabela 3 - Capacidades de Linguagem no Texto I- José

\begin{tabular}{l|c|c|c}
\cline { 2 - 4 } \multicolumn{1}{c|}{} & NAD & PAD & AD \\
\hline C.A & $X$ & & \\
C.D & $\mathrm{X}$ & & \\
C.L.D & $\mathrm{X}$ & & \\
\hline
\end{tabular}

Fonte: elaborada pelos autores.

\section{Segunda Produção: Hugo}

O texto II está idêntico ao primeiro, mesmo sendo teoricamente feito em grupo de três alunos, que parecem ter escolhido o texto do aluno Hugo como o mais adequado dentre as primeiras produções de todos.

$\mathrm{O}$ aluno ainda apresenta um texto parcialmente adequado, pois não houve diferenças além de correções gramaticais, ainda havendo inadequações.

Tabela 4 - Capacidades de Linguagem no texto II - Hugo

\begin{tabular}{l|c|c|c}
\cline { 2 - 4 } \multicolumn{1}{c|}{} & NAD & PAD & AD \\
\hline C.A & & $X$ & \\
C.D & & $X$ & \\
C.L.D & & $X$ & \\
\hline
\end{tabular}

Fonte: elaborada pelos autores.

Segunda Produção: Luiza

C.A. - AD

Esta produção, feita em grupo de três alunos, está adequada ao gênero proposto. Possui quatro parágrafos e todas as características necessárias, com ideias organizadas de modo coeso e coerente e um trocadilho no final da resenha, fazendo referência a uma música anterior da banda: "Sorry guys, but you will have to knock that door harder on the next time".

É caracterizada como uma resenha escrita por um não-jornalista, apresentando uma linguagem informal e descontraída, sem valorizar os aspectos técnicos do álbum e priorizando o que esse representa para os fãs.

\section{C.D. $-\mathrm{AD}$}

A resenha apresenta uma organização adequada, baseando-se na estrutura sugerida por Khunkitti (2005).

Inicialmente, 0 texto introduz a banda ("one of the biggest bands in the beginning of the 90's") também definindo-a quanto a seu gênero musical "Hard Rock". No segundo parágrafo, o album é apresentado, já com o começo de sua avaliação, no excerto "all the melodies that once fulfilled such passionate ballads that after two decades are still pounding the ears of GN'R fans are lost".

A avaliação se dá de forma mais visível no terceiro e quarto parágrafos, mesmo articulada a alguns elementos descritivos, como em "Even on the lyrics, they've changed to a "pissed off" bunch". No ultimo parágrafo, a resenha é finalizada sem uma conclusão, como por exemplo, uma recomendação do álbum, mas como um comentário negativo, como pode ser observado no excerto "all this lack of originality didn't make any good to these guys". 


\section{C.L.D. - PAD}

Apesar de possuir os aspectos linguísticos característicos de uma resenha, os alunos cometem algumas inadequações no uso do tempo verbal, como no excerto "Slash split up his relations with the band and go ahead with other groups", utilizando o presente do indicativo, visto que $o$ correto seria o pretérito perfeito. Também estão presentes alguns erros de escrita, como "May be" em vez de "Maybe".

Tabela 5 - Capacidades de Linguagem no Texto II - Luiza

\begin{tabular}{l|c|c|c}
\cline { 2 - 4 } \multicolumn{1}{c|}{} & NAD & PAD & AD \\
\hline C.A & & & $X$ \\
C.D & & & $X$ \\
C.L.D & & $\mathrm{X}$ & \\
\hline
\end{tabular}

Fonte: elaborada pelos autores.

\section{Segunda Produção: José}

\section{C.A. $-\mathrm{AD}$}

O aluno escreveu a sua segunda produção, juntamente a dois outros colegas, o que, em seu caso, deu resultado. José e seus colegas adicionam informações importantes em relação a banda ("the only members left are the lead singer and Dizzy Reed").

O texto apresenta elementos de avaliação do álbum ("the songs are heavy and Axl's voice is a little strange") e também da banda, como em "GNR still goes good", o que é essencial para a caracterização desta produção como pertencente ao gênero proposto em classe.
Com a opinião do resenhista exposta no texto, em "We really liked the new songs", a produção caracteriza uma resenha escrita por um fã, que contém vários detalhes pelos quais os leitores podem se interessar.

\section{C.D. $-\mathrm{AD}$}

Os movimentos de Khunkitti (2005) são facilmente identificados nessa segunda produção. Organizado em quatro parágrafos, o texto apresenta os cinco movimentos descritos pela autora.

A introdução (Movimento 1) está bem escrita, iniciando a escrita em relação à banda e contendo informações extras que contribuem para o entendimento da situação de produção do álbum ("Axl's voice went sour").

A descrição do álbum também está bem feita (Movimento 2), apresentando características comuns a todas as músicas do CD. Isso indica que os alunos fizeram uma pesquisa a respeito do álbum antes de escreverem seu texto final em sala de aula, o que contribuiu para a quantidade de detalhes presentes na produção.

Criticando o álbum e avaliando-o, no terceiro parágrafo (Movimento 3), os alunos acrescentam mais detalhes referente ao álbum: "The guitar solos keep wonderful and it combines with the lyrics". Além disso, expressam, explicitamente sua opinião sobre o álbum, implicando-se no texto, recomendando a produção (Movimento 4). 
O parágrafo final do texto está sucinto, adicionando algumas informações da banda (Movimento 5), como por exemplo em "some bands inspired themselves in Axl Rose, his style and his clothes".

\section{C.L.D - AD}

Os aspectos linguístico-discursivos do texto estão adequados ao gênero proposto, com elementos de descrição, como no excerto "with usually two guitar solos per music", ao descrever características das músicas do álbum Chinese Democracy.

Em "the guitar solos keep wonderful", os alunos apresentam a opinião sobre o álbum, com elementos de avaliação, assim como em "Axl's voice is a little strange". As inadequações gramaticais são poucas.

Tabela 6 - Capacidades de Linguagem no Texto II - José

\begin{tabular}{l|c|c|c}
\cline { 2 - 4 } \multicolumn{1}{c|}{} & NAD & PAD & AD \\
\hline C.A & & & $X$ \\
C.D & & & $X$ \\
C.L.D & & & $X$ \\
\hline
\end{tabular}

Fonte: elaborada pelos autores.

\section{Terceira Produção: Hugo}

C.A. $-\mathrm{AD}$

$\mathrm{O}$ aluno tem a possibilidade de resenhar alguma produção cultural de sua própria escolha, e decide por resenhar o álbum Death Magnetic da banda Metallica, a sua favorita. Apresenta informações referente à banda e a terceira produção escrita do aluno Hugo mostra tudo que aprendeu em sala de aula.
Baseando-se em exemplos de resenha vistos em sala de aula, o aluno reproduz uma resenha com características de uma produção jornalística, sem se implicar, mas criticando o álbum e recomendando-o após uma boa descrição do $\mathrm{CD}$, música por música, detalhando o máximo possível.

\section{C.D. $-\mathrm{AD}$}

Em uma introdução detalhada da Banda Metallica, o aluno apresenta o álbum Death Magnetic represents the band's attempt to return to their trash roots. Nos dois primeiros parágrafos introdutórios, apresenta mais detalhes sobre o álbum, por exemplo, "none of the album's 10 songs has less minutes". No terceiro parágrafo, já há uma avaliação por parte do aluno: "but the songs' sheer power is impressive and imposing".

Na sequência, o aluno apresenta uma descrição e avaliação de cada música do álbum, seguindo à risca a lista de passos trabalhados em sala de aula. Ao final, apresenta brevemente sua avaliação geral do álbum e o recomenda: "Like all the best heavy rock albums, it suspends your disbelief, demands your attention and connects directly with your inner teenager". A conclusão da resenha é sucinta, mas também bem feita, em "Metallica is back: not with a whimper, but a big bang", recomendando o álbum.

\section{C.L.D - AD}

O aluno utiliza um amplo vocabulário para descrever as músicas do álbum, com muitos adjetivos: "Single words are 
sung while a remarkable riff is played". As inadequações gramaticais são praticamente inexistentes.

Tabela 7 - Capacidades de Linguagem no texto III - Hugo

\begin{tabular}{l|c|c|c}
\cline { 2 - 4 } \multicolumn{1}{c|}{} & NAD & PAD & AD \\
\hline C.A & & & $X$ \\
C.D & & & $X$ \\
C.L.D & & & $X$ \\
\hline
\end{tabular}

Fonte: elaborada pelos autores.

\section{Terceira Produção: Luiza}

C.A. - PAD

Para a última produção, a aluna Luiza escolheu resenhar o filme "Seven Pounds". Nessa, apresenta o que aprendeu em sala de aula, com uma detalhada descrição e avaliação da obra. No entanto, comete um erro ao contar o final do filme. Nesse sentido, o intuito da resenha crítica era apresentara avaliação de uma obra e depois recomendá-la ou não, com a finalidade de ajudar o leitor da resenha se irá consumir um determinado produto, ao contar o final do filme em sua produção, o texto do resenhista não estará cumprindo satisfatoriamente a finalidade a que se destina.

\section{C.D. $-\mathrm{AD}$}

O texto, de cinco parágrafos, possui uma estrutura adequada ao gênero resenha crítica.

No primeiro, a aluna introduz o filme, descrevendo a impressão que o espectador pode ter do filme inicialmente ("its title that may give the impression that the film in related to money or something like that"), e, logo depois, discorrendo do que esse realmente trata ("a man named Ben Thomas (Will Smith), who caused a car crash").

Nessa detalhada descrição, a aluna também discorre sobre suas próprias impressões em relação ao personagem e como essas mudaram no decorrer do filme, como no excerto "I came to think that Ben Thomas was crazy or a bad guy".

Nos terceiro e quarto parágrafos, além de avaliar o ator principal ("Will Smith does an excellent interpretation as Ben”), apresenta a sua avaliação acerca do filme, em 'Seven Pounds' is a great movie, with a very well thought-out script".

No parágrafo final, a aluna finaliza a sua produção recomendando o filme e apresentando outras características desse: "I recommend it to anyone who likes movies with good content and an ingenious story".

\section{C.L.D - PAD}

Quanto aos aspectos linguísticos, a aluna faz um bom uso da linguagem argumentativa e avaliativa, utilizando corretamente o uso do presente do indicativo ao descrever o filme, servindo-se de vários adjetivos. Luiza, porém, comete algumas inadequações simples, traduzindo as ideias do português para o inglês, como, por exemplo, em "This is a beautiful story mysterious", colocando o adjetivo após o substantivo, quando o correto seria colocá-lo antes, e "He left your heart to Emily", estrutura na qual 
o uso correto seria his em vez de your.

Há, também, a colocação de vírgulas em lugares indevidos, como em "Anyway, 'Seven Pounds', is a great movie”, uma vez que a segunda vírgula não deveria existir, pois não se separa sujeito do verbo com vírgula.

Tabela 8 - Capacidades de Linguagem no Texto III - Luiza

\begin{tabular}{c|c|c|c}
\hline & NAD & PAD & $A D$ \\
\hline C.A & & $X$ & \\
C.D & & & $x$ \\
C.L.D & & $\mathrm{X}$ & \\
\hline
\end{tabular}

Fonte: elaborada pelos autores

\section{Terceira Produção: José}

\section{C.A. - AD}

Para sua terceira produção, o aluno José escolheu resenhar a série "The Arthur Books - The Winter King", de Bernard Cornwell, e produziu um texto adequado às especificidades do gênero proposto.

A produção apresenta uma descrição detalhada da trilogia, bem como uma avaliação da mesma. Este texto, ao contrário das duas anteriores do aluno, não apresenta implicação do autor, caracterizando uma resenha jornalística.

\section{C.D. - AD}

O texto é organizado em três parágrafos, que apresentam os cinco movimentos propostos por Khunkitti (2005).

No primeiro, o aluno apresenta uma introdução da trilogia (Movimento 1), com informações extras de outros trabalhos do autor (Movimento 5), como no excerto "best known for his novels about Napoleonic Wars rifleman Richard Sharpe".

No segundo parágrafo, relata uma descrição da história da trilogia, por exemplo, em "Britain is in serious danger because the Saxons are trying to conquer it". Por fim, no terceiro e último parágrafos, José apresenta uma avaliação ("He also puts you on the battlefield with Arthur and Derfel by his amazingly detailed scenes"), além de concluir sua resenha recomendando a obra.

\section{C.L.D - AD}

A produção de José apresenta as características linguísticas específicas do gênero resenha crítica nessa última produção, com uma linguagem descritiva nos dois primeiros parágrafos e opinativa no último.

Para tal, o aluno descreve de forma coesa a trilogia escolhida, como no excerto a seguir: "The trilogy is narrated by Derfel, who witnesses everything from the beginning, when Uther, the High King of Britain is dying and begging to the gods for an heir. Mordred came, as a crippled king, but as a child he couldn't rule anything”.

Em sua avaliação da obra, o aluno utiliza variados adjetivos e, por vezes, advérbios, como em "He also puts you on the battlefield with Arthur and Derfel by his amazingly detailed scenes". 
Tabela 9 - Capacidades de Linguagem no Texto III - José

\begin{tabular}{l|c|c|c}
\cline { 2 - 4 } \multicolumn{1}{c|}{} & NAD & PAD & AD \\
\hline C.A & & & $X$ \\
C.D & & & $X$ \\
C.L.D & & & $X$ \\
\hline
\end{tabular}

Fonte: elaborada pelos autores.

Pode-se observar um salto tanto qualitativo como quantitativo entre a primeira e última produção do aluno Hugo. Na primeira, a breve avaliação apresentada sobre o álbum demonstra que ele, apesar de ter algum conhecimento do gênero proposto, não desenvolve suas ideias adequadamente. A motivação pode ter sido um fator influenciador na qualidade de seu trabalho.

A mesma situação é observada em sua segunda produção. Mesmo com o desenvolvimento da sequência didática, Hugo não se sente motivado a produzir um segundo texto referente ao mesmo álbum, fazendo apenas correções gramaticais em sua primeira produção.

A aprendizagem do aluno pode ser notada, porém, na última produção. $\mathrm{O}$ primeiro texto possuía menos de uma página, enquanto o terceiro possui três, além de conter também a logomarca da banda e uma avaliação muito mais detalhada. O fato de Hugo avaliar o álbum da Banda Metallica, sua favorita, pode tê-lo motivado a escrever um texto melhor, utilizando os conhecimentos adquiridos em sala de aula, tanto no que diz respeito ao conteúdo e sua organização quanto aos recursos da linguagem para o objetivo ser alcançado.
Em questões teóricas, podemos relacionar o desenvolvimento de Hugo à utilização de textos que circulam no meio social (CRISTOVÃO, 2009). A possibilidade de resenhar um álbum de seu gosto, revelouo sucesso do conteúdo trabalhado em sala de aula e interesses de seu cotidiano.

A análise das produções de Luiza mostra-nos que a segunda produção, ao contrário do que observamos com Hugo, foi importante para o seu desenvolvimento.

No primeiro texto, sem conhecer o álbum trabalhado em classe, a aluna avaliou a banda Guns n' Roses em apenas um parágrafo. Já na segunda produção, ao ter a experiência de se juntar com dois outros colegas, seu texto contém muitas outras informações relacionadas com a banda, além de uma avaliação bastante crítica do álbum Chinese Democracy.

Luiza mostra que, além da sequência didática, esse contexto foi importante em sua última produção, que resultou em um texto muito mais organizado que seu primeiro e com uma maior utilização de recursos linguístico-discursivos. Comete um deslize ao contar o final do filme, mas, mesmo assim, mostra uma considerável aprendizagem do gênero.

O desenvolvimento de Luiza, ao observar os seus quadros analíticos, pode ser atribuído à experiência de ter se juntado a outros colegas no decorrer da SD. Isso fica aparente no salto qualitativo em suas Capacidades de Ação e Capacidades Discursivas. É possível dizer, portanto, que os gêneros textuais contribuíram 
para o seu desenvolvimento por meio do trabalho coletivo e da "integração de diferentes ações de linguagem (leitura, produção escrita etc.) e de conhecimento diversos" (CRISTOVÃO, 2009, p. 4).

Por fim, mesmo que o aluno José apresente apenas uma pequena diferença quantitativa entre a primeira e a última produção, o aprendizado é facilmente percebido na leitura dos textos.

Na primeira produção, José demonstrou um pequeno conhecimento da banda Guns n' Roses, revelando um desconhecimento do álbum Chinese Democracy e de como produzir uma resenha. Já na segunda produção, parte da pequena introdução é aproveitada, e juntamente a outros três colegas, José produz um texto adequado ao gênero proposto, com uma ótima avaliação do álbum.

Em seu último texto, o aluno mostra o seu aprendizado através de uma produção detalhada, uma resenha de apenas três parágrafos, mas muito bem escrita. Podemos observar nesse aluno a evolução mais linear dentre os três alunos que tiveram suas produções analisadas, e por isso, podemos considerar a sequência didática em si como o fator mais importante para o desenvolvimento do aluno José; os gêneros possibilitaram uma "progressão a partir de trabalho individual e coletivo" (CRISTOVÃO, 2009, p. 4).

Conseguimos observar, nos três indivíduos que compuseram o grupo focal desta pesquisa, uma evolução na argumentação e na linguagem avaliativa, demonstrando a aprendizagem do gênero resenha crítica, segundo os referenciais teóricos utilizados neste estudo. Cada um dos indivíduos, com suas características particulares, teve um diferente fator chave para o seu desenvolvimento: no caso de Hugo, a motivação em resenhar um álbum de sua banda favorita; Luiza, por outro lado, a experiência em produzir a segunda resenha com outros colegas; e por fim, José, a sequência didática em si.

Por mais que tais alunos tenham atingido o seu objetivo por meios diferentes, o trabalho com o gênero foi bem sucedido quanto às contribuições deste aprendizado para a formação do aluno. Além de desenvolverem a sua habilidade escrita, analisando criticamente um bem cultural, o trabalho com a sequência didática é algo que o aluno pode (re)produzir em classe, sendo ele um futuro professor.

\section{Considerações finais}

Os três alunos do grupo focal desta pesquisa, Hugo, José e Luiza, desenvolveram suas capacidades de linguagem para produção escrita e apropriaram-se adequadamente do gênero resenha crítica. A sequência didática com base em gêneros foi efetiva, uma vez que foi possível observar fatores como motivação e possibilidade de ação decorrentes da utilização de textos autênticos em sala de aula. Além disso, devido à individualidade de cada aluno, as características do gênero focam apropriadas através de diferentes caminhos, demonstrando a importância das escolhas dos indiví- 
duos (BRONCKART, 2006) para o seu desenvolvimento.

Concluímos que o gênero resenha crítica traz contribuições teóricas, metodológicas e políticas significativas, ao engajar o aluno em atividades de avaliação crítica de um bem cultural. Tanto a leitura quanto a escrita de resenhas críticas, envolvem o futuro professor em práticas sociais concretas que podem ser usadas para a formação do aluno, tanto na educação básica quanto na educação inicial do professor de inglês.

Tal aprendizagem ajuda os alunos a analisar de maneira crítica não apenas uma obra literária, cinematográfica ou musical, mas também outros textos aos quais ele é exposto durante sua formação; o desenvolvimento da consciência crítica não é restrito apenas ao contexto ao que foram expostos na sequência didática. A perspectiva teórica do ISD (BRONCKART, 2006, 2008) pode ser aplicada a qualquer gênero textual, proporcionando uma criticidade decorrente da utilização da abordagem sociointeracionista.

Por fim, a possibilidade de disseminação de seus textos escritos representa uma oportunidade de participação social ativa em práticas letradas, participação essa que é essencial para o exercício da cidadania e para o desenvolvimento do aprendizado.
The role of writing and reading critical reviews of books, movies and $\mathrm{CD}$ in the initial education of the English teacher

\section{Abstract}

In this paper, we investigate the connection between the genre critical (movie / book / CD) reviews and teacher education, as well as their contributions to the professional development of future teachers. Within this broader purpose, we limited our objectives to: i) identifying the adequacy of the texts produced by students of Modern Foreign Languages at a public university in Northern Parana to the characteristics of each genre used in class; and ii) analyzing the contribution of the process of reading and writing texts belonging to such genres for their professional development. The genre was used in class through a didactic sequence consisting of activities for learning the characteristics of critical reviews as well as three written productions, which allowed the observation of the development of written language of these individuals. The didactic sequence is considered a relevant tool in the learning process of these students, but the results point peculiarities in the development of each individual who composes the focus group in this study. The theoretical and methodological referential in which we base our studies is the Sociodiscursive interactionism (BRONCKART, 2006, 2008).

Keywords: Text genres. Teacher education. Sociodiscursive interactionism. Critical (books/CD/films) review. 


\section{Notas}

1 O presente trabalho fez parte do projeto de Gêneros Textuais e Educação Inicial do Professor de Língua Inglesa, o GENTEDIPLI, que buscou identificar o papel dos gêneros textuais no desenvolvimento do aluno em um contexto acadêmico de formação de professores de língua estrangeira.

2 Charoenschasri (2006, p. 12). Tradução minha.

\section{Referências}

BAKHTIN, M. Estética da criação verbal. São Paulo: Martins Fontes, 1992.

BARRAS, R. Os cientistas precisam escrever: guia redação para cientistas, engenheiros e estudantes. 2. ed. São Paulo: T. A Queiroz, 1986.

BARROS, E. M. D. Gêneros textuais e práticas de letramento: a temporalidade verbal no gênero crítica cinematográfica. Revista Brasileira de Linguística Aplicada, Belo Horizonte, v. 9, n. 1, p. 177-200, 2009.

BERBARE, A. P. Crítica de cinema: caracterização do gênero para projetos de produção escrita na escola. In: LOPES-ROSSI, M. A. (Org.). Gêneros discursivos no ensino de leitura e produção de textos. Taubaté: Cabral, 2004. p. 41-58.

BRASIL. Parâmetros curriculares nacionais: terceiro e quarto ciclos do ensino fundamental: língua estrangeira / Secretaria de Educação Fundamental. Brasília, DF: MEC/ SEF, 1998.

BRONCKART, J. P. Atividade de linguagem, textos e discursos: por um interacionismo sócio-discursivo. Trad. Anna Rachel Machado e Péricles Cunha. São Paulo: EDUC, 1999.

. Atividade de linguagem, discurso e desenvolvimento humano. Trad. Anna Rachel Machado e Maria Lucia Meirelles Matêncio. Campinas, SP: Mercado de Letras, 2006.
O agir nos discursos: das concepções teóricas às concepções dos trabalhadores. Trad. de Anna Rachel Machado e Maria Lucia Meirelles Matêncio. Campinas: Mercado de letras, 2008.

CHAROENCHASRI, C. Genre analysis of newsgroup movie reviews on www. Imdb. com, 2006. Disponível em: <http://www. huso.buu.ac.th/Conference/HUSO50/file/ Chayanin\%20-\%20Genre\%20Analysis\%20 of $\% 20$ Newsgroup $\% 20$ Movie $\% 20$ Reviews $\% 20$ ...doc>. Acesso em: 4 abr. 2014.

CRISTOVÃO, V. L. L. Sequências didáticas para o ensino de línguas. In: DIAS, R.; CRISTOVÃO, V. L. L. (Orgs.). O Livro didático de língua estrangeira: múltiplas perspectivas. Campinas: Mercado de Letras, 2009. p. 305-344.

KHUNKITTI, W. Genre analysis of book reviews in journals in the english language field. 2005. Tese (Master of Art), Kasetsart University, 2005.

MOTTA-ROTH, D. Rhetorical features and disciplinary cultures: a genre-based study of academic book reviews in linguistics, chemistry and economics. 1995. Tese (Doutorado em Linguística Aplicada) - Universidade Federal de Santa Catarina, Florianópolis, 1995.

DOLZ, J.; SCHNEUWLY, B. Gêneros orais e escritos na escola. Trad. e org. Roxane Rojo e Glaís Sales Cordeiro. Campinas: Mercado de Letras, 2004.

SWALES, John M. Genre analysis: english in academic and research settings. Cambridge: Cambridge University Press, 1990.

VIAN JUNIOR, O.; IKEDA, S. N. O ensino do gênero 'resenha' pela abordagem sistêmico-funcional na formação de professores. Linguagem \& Ensino, Pelotas, v. 12, n. 1, p. 13-32, jan./jun. 2009. 